\title{
"Se não bater, não aprende": educação e direitos da criança e do adolescente em Angola
}

\author{
"If not beaten, we do not learn": education and children's rights in Angola
}

"Si no nos golpean, no aprendemos": educación y derechos del niño en Angola

\author{
AIRI MACIAS SACCO* \\ ClÉA MARIA DA SILVA FERREIRA** \\ SÍlVIA HELENA KOLLER ${ }^{* * *}$
}

\begin{abstract}
RESUMO
O objetivo deste artigo é investigar a situação dos direitos da criança e a utilização de castigos físicos em escolas de ensino público primário de Angola. Foram realizados dois estudos, um quantitativo e outro qualitativo, e ambos tiveram como plano de fundo metodológico a inserção ecológica. Participaram do estudo quantitativo 241 crianças e adolescentes. Os resultados revelaram que a maioria já foi vítima de algum tipo de agressão física cometida por professores ou ficou de castigo na escola. No estudo qualitativo, as crianças e os adolescentes foram unânimes ao relatar o uso de castigos físicos e, apesar de não gostarem de ser castigadas, muitas afirmaram acreditar que estes são necessários para a aprendizagem. Elas também identificaram precariedade infraestrutural, escassez de material escolar e falta de água, energia elétrica e merenda. O respeito aos direitos da criança ainda é incipiente em Angola como um todo e nas escolas em particular.
\end{abstract}

Palavras-chave: Educação. Direitos da criança. Castigos físicos. Angola.

\section{AbSTRaCT}

This paper aimed to assess the situation of children's rights and the existence of corporal punishment in Angolan public primary schools. Both studies 1 and 2 used the ecological engagement as a methodological background. In study 1 , quantitative, most of the 241 participants, children form 9 to 18 years old, said that at least once they have been grounded or victims of corporal punishment by teachers. In study 2, qualitative, all participants said that corporal punishment is frequently used in their schools. Although they do not like it, many of them said that this kind of punishment is a requisite for the learning process. Participants also identified infrastructural problems and lack of school suplies, water, electricity and food at the schools. Children's rights are still incipient in Angola as a country and in the schools in particular.

Keywords: Education. Children's rights. Corporal punishment. Angola.

\section{RESUMEN}

El objetivo de este artículo es investigar la situación de los derechos del niño y la utilización de castigos físicos en escuelas primarias públicas de Angola. Fueron realizados dos estudios, uno cuantitativo y otro cualitativo; ambos tuvieron como base metodológica la inserción ecológica. Participaron del estudio cuantitativo 241 niños y adolescentes. Los resultados indicaron que la mayoría ya ha sido víctima de algún tipo de agresión física cometida por profesores o quedó castigado en la escuela. En el estudio cualitativo, los niños y adolescentes fueron unánimes al relatar la utilización de castigos físicos y, a pesar de no querer ser castigados, muchos afirmaron creer que los castigos son necesarios para el aprendizaje. También identificaron precariedad de infraestructuras, escasez de materiales escolares, falta de agua, energía eléctrica y merienda. El respeto a los derechos del niño todavía es incipiente en Angola como país y en las escuelas en particular.

Palabras clave: Educación. Derechos del niño. Castigos físicos. Angola.

\footnotetext{
*Psicóloga, Mestre e Doutoranda do Programa de Pós-Graduação em Psicologia da Universidade Federal do Rio Grande do Sul. E-mail: <amsacco@ gmail.com>.

** Pedagoga e Mestre em Educação pela Universidade de São Paulo; Doutoranda em Educação na Pontifícia Universidade Católica do Rio de Janeiro (PUC-Rio).E-mail: <clea@usp.br>.

***Psicóloga e Doutora em Educação, Professora Associada do Instituto de Psicologia da Universidade Federal do Rio Grande do Sul. E-mail: <silvia.koller@ gmail.com>.
} 
Angola localiza-se na costa ocidental da África e constitui-se de aproximadamente 20 milhões de habitantes (Programa das Nações Unidas para o Desenvolvimento PNUD, 2013). Antiga colônia portuguesa, o país esteve envolvido em uma sequência de guerras - primeiro pela independência e depois uma guerra civil -, que terminaram apenas em 2002. O período de mais de 40 anos de conflito armado, além de ter sido um obstáculo ao desenvolvimento do país, deixou marcas profundas na população, que aprendeu a conviver com transgressões cotidianas dos direitos humanos, como geralmente acontece em tempos de guerra (SALMÓN G., 2007). Além das mortes diretas, esses tipos de conflito também provocam desalojamentos, destruição de infraestruturas, precariedade de serviços básicos e uma série de consequências negativas em âmbitos políticos, econômicos e, principalmente, sociais (GATES; HEGRE; NYGARD et al., 2012).

No caso específico de Angola, essas diversas consequências dos conflitos armados podem ser percebidas nos indicadores de desenvolvimento do país. De acordo com dados de 2013 do Programa das Nações Unidas para o Desenvolvimento (PNUD), a população angolana tem média de 16,6 anos de idade e a nona menor expectativa de vida do mundo: 51,5 anos. O Índice de Desenvolvimento Humano (IDH) de Angola é de 0.508, considerado baixo (PNUD, 2013). O IDH é calculado com base no Produto Interno Bruto (PIB) per capita, na longevidade da população e nas taxas de analfabetismo e matrícula em todos os níveis de ensino. Além disso, 50\% da população não tem acesso à água potável, $73,8 \%$ não tem energia elétrica (PNUD, 2013) e 54,3\% sobrevive com uma renda de até US\$ 1,25 por dia (PNUD, 2010).

Os direitos humanos, especialmente os direitos da criança, são frequentemente violados em situações de conflito armado (MACHEL, 1996; ONYANGO, 1998, ONU, 2000). A falta de acesso a recursos básicos, como luz e água, a vida em condição de pobreza extrema, a exposição a minas terrestres, a precariedade das estruturas de saúde e educação, dentre outras consequências das guerras, constituem graves violações dos direitos humanos às quais as crianças são especialmente vulneráveis (CONSTANZA apud FRAGA, 2006; ONU, 2000) por estarem, como preconizado pela Convenção sobre os Direitos da Criança (CDC), em um período peculiar do desenvolvimento humano e precisarem de atenção e cuidados especiais (ONU, 1989).

A CDC é o tratado internacional de direitos humanos mais ratificado da história da ONU e assegura que todas as crianças, sem qualquer tipo de discriminação, devem ter garantido o acesso aos seus direitos civis, políticos, econômicos, sociais e culturais (ONU, 1989). Na CDC estão estabelecidos os direitos fundamentais das crianças à provisão, à proteção e à participação. A provisão refere- se ao direito à alimentação, ao cuidado e à educação, entre outros. Na proteção estão especificados os direitos a não sofrer abusos, maus-tratos ou negligências, bem como exploração. Já a participação garante às crianças o direito de expressar suas opiniões e de fazer parte das decisões que, de alguma forma, afetarão suas vidas (VERHELLEN, 2000).

Os direitos da criança constituem um tema relativamente recente na história da humanidade. Até o fim do século XIX, as crianças não eram vistas como sujeitos de direitos e nem como pessoas em um estágio peculiar de desenvolvimento. Em 1874, Mary Ellen Wilson, de 9 anos, foi sistematicamente torturada e violentada por sua madrasta nos Estados Unidos. A ausência de leis de proteção à criança tornou necessário recorrer à Sociedade Americana de Prevenção à Crueldade contra os Animais para que a menina fosse salva. Esse caso é considerado um marco a partir do qual surgiram diversas entidades de defesa dos direitos da criança em todo o mundo (SHELMAN; LAZORITZ, 2005).

Na segunda década do século XX, após o término da I Guerra Mundial, a Liga das Nações, entidade precursora da ONU, adotou a Declaração de Genebra dos Direitos da Criança (SOUZA, 2001). Essa declaração referese aos deveres da sociedade com relação às crianças, mas não menciona os direitos da criança, que constam com essa nomenclatura apenas no título do documento (LEAGUE OF NATIONS, 1924). As crianças, nesse caso, foram consideradas objetos de direitos, e não sujeitos de direitos. Devido ao contexto da época, o documento não teve a repercussão e o impacto necessários para ser aceito e consolidado. Apesar disso, correspondeu à primeira iniciativa para o reconhecimento internacional dos direitos da criança (SOUZA, 2001).

Em 1948, a ONU promulgou a Declaração Universal dos Direitos Humanos. Embora não tenha nenhum artigo especificamente voltado às crianças, o parágrafo $2^{\mathrm{O}}$ do Artigo 25 menciona que “(...) a infância tem direito a cuidados e assistência especial" (ONU, 1948). Esse parágrafo foi o germe para a elaboração da Declaração dos Direitos da Criança, proclamada pela ONU, em 1959, marcando o início de uma reviravolta no que diz respeito aos direitos infanto-juvenis, pois as crianças, a partir de então, começaram a ser percebidas como sujeitos de direitos. Em seu preâmbulo, a declaração afirma que "a humanidade deve à criança o melhor de seus esforços". Os dez princípios do documento fazem referência aos direitos da criança à não discriminação, à proteção, ao desenvolvimento, à liberdade, à dignidade, à nacionalidade, à saúde, ao cuidado, à recreação, ao amor, à segurança e à educação, entre outros (ONU, 1959).

Apesar de ter apresentado ideias inovadoras no que diz respeito aos direitos da criança, a Declaração de 1959 
não foi efetiva na consolidação desses direitos. Essa efetividade foi atingida apenas 30 anos depois, quando, em 1989, a ONU adotou, em Assembleia Geral, a CDC como sua Carta Magna para a proteção de todas as crianças (SOUZA, 2001). Angola ratificou a CDC no dia 5 de dezembro de 1990. O país também ratificou a Carta Africana dos Direitos e Bem-Estar da Criança em 11 de abril de 1992.

Além desses documentos internacionais, o apoio oficial angolano à questão dos direitos da criança está presente na constituição do país. No parágrafo $6 \underline{0}$ do Artigo 35 da Constituição angolana consta que "a proteção dos direitos da criança, nomeadamente, a sua educação integral e harmoniosa, a proteção da sua saúde, condições de vida e ensino constituem absoluta prioridade da família, do Estado e da sociedade" (ANGOLA, 2010). No entanto, apesar dessas quase duas décadas (são mais de duas décadas desde 1990) de reconhecimento nacional aos direitos infantis, as crianças angolanas continuam sofrendo com violações rotineiras de seus direitos mais básicos, como o direito à vida, à alimentação, à educação e à proteção. Segundo estimativas do Pnud (2013), Angola tem uma das dez maiores taxas de mortalidade infantil do mundo: 98 mortes para cada 1.000 bebês nascidos vivos. O mesmo ocorre com o índice de mortalidade das crianças com até 5 anos, segundo o qual 161 crianças, de cada 1.000 nascidas vivas, morrem antes de completar o quinto ano de vida (PNUD, 2013). Além disso, das crianças com até 5 anos de idade, $31 \%$ estão abaixo do peso ideal (PNUD, 2010).

As crianças angolanas enfrentam cotidianamente uma série de obstáculos ao seu desenvolvimento, que englobam tanto aspectos relacionados à provisão quanto à proteção e à participação. Esses entraves começam já com a dificuldade de acesso ao registro de nascimento. Em 2007, foi criado o Conselho Nacional da Criança (CNAC), órgão relacionado às políticas públicas de promoção e defesa dos direitos da criança. As áreas críticas dos direitos da criança no país, e por isso elencadas como prioritárias pelo CNAC, foram: esperança de vida ao nascer; registro de nascimento; acesso à alimentação; educação da primeira infância; ensino fundamental e formação profissional; justiça juvenil; prevenção e redução do impacto do HIV/AIDS nas famílias e nas crianças; prevenção e mitigação da violência contra a criança; proteção social; promoção de cultura e esporte; e inclusão da criança no Plano Nacional e no Orçamento Geral do Estado (CNAC, 2009).

No que diz respeito especificamente à educação, enfatizada pelo Cnac, a evolução do sistema de ensino como um todo foi muito afetada durante as guerras (MED, 2010a). Uma pesquisa realizada na África Subsaariana, onde Angola se localiza, verificou que os conflitos armados tiveram forte influência negativa sobre o sistema de ensino dos países em que houve guerra (POIRIER, 2012). Em Angola, a população adulta tem escolaridade média de 4,7 anos, o que corresponde ao ensino primário incompleto, e $30 \%$ dos angolanos com 15 anos ou mais não são alfabetizados (PNUD, 2013) - número que não leva em consideração o analfabetismo funcional.

Após o término da guerra civil, em 2002, o Ministério da Educação de Angola (MED) identificou um aumento considerável no número de alunos matriculados nas escolas do país. De 2002 a 2008, o ensino primário recebeu um acréscimo de aproximadamente 2 milhões de matrículas. Também foram incorporados novos integrantes ao corpo docente: de 2002 a 2010, ocorreu a contratação de 166.460 novos professores. Apesar disso, o próprio MED (2010a) reconheceu que "foram recrutados alguns professores sem o nível acadêmico e pedagógico aceitável, principalmente para as escolas do meio rural" (p. 10). A formação insuficiente do corpo docente, que não recebe treinamento adequado para lecionar (SACCO, 2011), acarreta a utilização de poucas estratégias de ensino e o despreparo para lidar com alunos que apresentem necessidades especiais. Esses profissionais são pouco valorizados e muitas vezes não têm acesso aos materiais didáticos necessários ao exercício de suas atividades (MED, 2010a, 2010b).

Aliado a isso, algumas das principais dificuldades do sistema de ensino público primário angolano estão relacionadas à insuficiência de recursos financeiros, materiais e humanos, à precariedade das infraestruturas, à diversidade linguística e à baixa qualidade do ensino. Muitas escolas não têm mobília e manutenção adequadas, além de existir um elevado número de salas de aula ao ar livre (MED, 2010a, 2010b). A comunidade escolar também enfrenta falta de merenda, de água potável e de energia elétrica na maioria das instituições de ensino público primário (CNAC, 2009).

Com base em um diagnóstico realizado em 1986, o MED elaborou uma Reforma Curricular, que começou a ser implantada em 2003, com o objetivo de melhorar a qualidade da educação e torná-la acessível a um maior número de pessoas. De acordo com a reforma, o ensino primário compreende da primeira até a sexta classe e é gratuito e obrigatório para crianças a partir de 6 anos de idade (MED, 2010a). Além disso, foi responsável por proibir a utilização de castigos físicos e violência nas escolas, artifícios socialmente aceitos e tradicionalmente adotados nas salas de aula angolanas (SAVE THE CHILDREN, 2010). Segundo Feinstein e Mwahombela (2010), mesmo proibidos na maioria dos locais, os castigos físicos também são muito utilizados em escolas de outros países africanos, como África do Sul, Quênia, Suazilândia e Tanzânia. 
Alguns dos castigos mais comuns nas instituições de ensino público primário de Angola consistem em colocar as crianças ajoelhadas em cima de pequenas pedras com os braços abertos e segurando pedras nas mãos, bater em suas pernas, nádegas e braços com pedaços de pau ou mangueiras, puxar suas orelhas e obrigá-las a limpar salas de aula, banheiros e outras dependências da escola (MED, 2010b). Esses artifícios são utilizados pelos docentes e defendidos não só por eles, mas também por muitos pais e responsáveis pelos alunos, com o argumento de que promovem a disciplina e a aprendizagem (SACCO, 2011).

Em Angola, a proibição da utilização de métodos violentos contra os estudantes nas escolas partiu de uma mudança no sistema de ensino do país, mas teve reflexos na sociedade como um todo, a partir do momento em que situou a criança e o adolescente efetivamente como sujeitos detentores de direitos. No entanto, a despeito das modificações na legislação, a sociedade por vezes é orientada por suas próprias leis informais, que não necessariamente correspondem àquelas formuladas pelo governo, ainda mais quando dizem respeito a crenças e hábitos enraizados ao longo do tempo (WEBER; GUZZO, 2009).

Dessa forma, o objetivo desta pesquisa foi compreender, por meio de dois estudos, um quantitativo e outro qualitativo, a situação atual dos direitos da criança em escolas de ensino público primário de Angola, tomando como base a CDC e dando ênfase à investigação da ocorrência de castigos físicos nessas instituições. Além disso, a pesquisa teve como intuito conhecer a opinião de crianças e adolescentes angolanos a respeito das escolas nas quais estudam.

Ambos os estudos tiveram como plano de fundo metodológico a inserção ecológica (CECCONELLO; KOLLER, 2003, 2004; ESCHILETTI PRATI et al., 2008; PALUDO; KOLLER, 2004). Adequada para o estudo do desenvolvimento-no-contexto, a inserção ecológica é uma sistematização da Teoria Bioecológica do Desenvolvimento Humano (TBDH), desenvolvida por Bronfenbrenner $(1979,2005)$. Essa proposta tem como base o engajamento dos pesquisadores no ambiente estudado, com o objetivo de estabelecer proximidade com a realidade dos participantes e, assim, ter melhores condições de responder às questões propostas (CECCONELLO; KOLLER, 2003, 2004).

A inserção ecológica prima pela busca constante da validade ecológica dos dados (CECCONELLO; KOLLER, 2003). Considerando que o contexto está relacionado à percepção da pessoa sobre o ambiente, e não apenas às características objetivas que ele possa ter (BRONFENBRENNER, 2005), a validade ecológica implica tentar entender como os participantes vivenciam o contexto no qual estão imersos (BRONFENBRENNER, 1979). A inserção ecológica funciona como uma ferramenta que auxilia os pesquisadores a alcançar uma melhor compreensão sobre o tema que estão estudando. Permite que eles participem do ambiente analisado, tenham acesso ao cotidiano dos participantes e possam, dessa forma, vivenciar a subcultura da qual fazem parte as pessoas em questão (PALUDO; KOLLER, 2004). Esse contato aumenta a probabilidade de que os pesquisadores interpretem de forma coerente a realidade analisada, visto que este possibilita uma aproximação da maneira pela qual cada participante vivencia, subjetivamente, essas propriedades.

No caso desta pesquisa ${ }^{1}$, a inserção teve duração de quatro meses, nos quais as pesquisadoras entraram em contato com o contexto angolano de modo geral, e particularmente com o sistema de ensino público primário, em seus variados aspectos socioeconômicos, históricos e culturais. Ela não se restringiu, portanto, ao período de coleta de dados nas escolas. A equipe permaneceu durante três meses em Luanda, sede da pesquisa, uma semana em cada uma das outras províncias e um dia em cada escola. Os detalhes metodológicos e os resultados de cada estudo serão apresentados separadamente. A discussão, no entanto, será realizada de maneira integrada.

\section{ESTUDO I}

O objetivo deste estudo foi realizar um levantamento sobre a ocorrência de castigos físicos em escolas de ensino público primário de Angola. Além disso, o estudo também teve como intuito conhecer a trajetória acadêmica dos estudantes dessas instituições.

\section{Método}

Este estudo, de delineamento quantitativo, englobou 15 escolas de ensino público primário situadas em cinco das 18 províncias angolanas: Bié, Cunene, Huíla, Luanda e Moxico. Nessas escolas, participaram da pesquisa 241 crianças e adolescentes, entre 9 e 18 anos de idade $(M=13,27, S D=2,08)$, sendo que $44,3 \%$ eram meninas. A participação ocorreu de forma voluntária, e todos, crianças e adolescentes, foram informados sobre os objetivos do estudo. Além disso, foi garantida a sua liberdade para interromper a participação em qualquer

\footnotetext{
1 Este estudo é parte integrante de uma pesquisa maior, concebida como resultado de acordo de cooperação entre o Unicef e o Ministério da Educação de Angola para a implantação do Programa Escolas Amigas da Criança no país. A pesquisa foi desenvolvida por equipe multidisciplinar de especialistas brasileiros nas áreas de psicologia, educação, direitos humanos, relações internacionais e economia. Todos os profissionais que fizeram parte da equipe de campo e de elaboração dos relatórios e recomendações de ações eram residentes em Angola, com exceção das autoras deste estudo.
} 
momento da coleta de dados, sem que isso acarretasse qualquer tipo de dano para si ou para outros.

Os participantes responderam a um questionário produzido especificamente para este estudo. $\mathrm{O}$ instrumento era composto por 39 questões de múltipla escolha, abordando itens sociodemográficos e temas como trajetória escolar, envolvimento da família com o cotidiano escolar, situações de violência, relação com a escola e expectativas de futuro acadêmico. Os questionários foram aplicados de maneira coletiva, em sala de aula. Inicialmente, a ideia era que as instrutoras só dessem instruções gerais e ficassem à disposição para esclarecer dúvidas. No entanto, a maioria das crianças e adolescentes, mesmo em séries mais avançadas, apresentava muitas dificuldades de leitura. Assim, as pesquisadoras optaram por ler cada pergunta e suas respectivas alternativas para que, individualmente, os participantes marcassem suas respostas. Cada aplicação demorou em torno de duas horas.

\section{Resultados}

A maioria das crianças e adolescentes $(80 \%)$ afirmou morar em residências com cinco ou mais pessoas. Apesar de não serem os principais provedores da casa, $20 \%$ disseram trabalhar para ajudar no sustento da família. Para $44 \%$ desses, o trabalho dificultava os seus estudos, índice que pode ter colaborado para a alta defasagem escolar identificada (ver Gráfico 1). Esse fenômeno parece estar relacionado principalmente ao elevado número de reprovações dos alunos, visto que $60,4 \%$ dos participantes declararam ter sido reprovados ao menos uma vez durante sua trajetória acadêmica. Também contribuiu para essa defasagem o fato de $16,6 \%$ dos alunos ter precisado interromper os estudos em algum momento. É interessante notar que, por envolver o preenchimento de um questionário, só participaram deste estudo as crianças e adolescentes que declararam saber ler e escrever. O Gráfico 1 revela, portanto, que a alfabetização parece ocorrer de forma mais concreta apenas a partir do 4으o ano, e ainda assim com ressalvas, já que a acentuada dificuldade de leitura apresentada pelas crianças teve inclusive reflexos sobre os procedimentos do estudo, como explicitado no método.

Mais de um terço dos participantes não soube dizer qual era o nível de escolaridade de seus pais ou responsáveis. No que diz respeito ao envolvimento da família com os seus estudos, $67,2 \%$ disseram que os pais ou responsáveis acompanham suas atividades escolares. Em contrapartida, apenas 37,7\% afirmaram que algum de seus cuidadores conhecia seus professores.

Com relação à utilização de castigos físicos, 76,3\% das crianças e adolescentes declararam já ter sofrido pelo menos uma das seguintes agressões de um professor: puxões de orelha, tapas na cabeça ou nas mãos e golpes com mangueira ou pedaço de pau. Além disso, 37,7\% relataram já ter ficado de castigo na escola. Ainda no que diz respeito a violações de direitos, $18,6 \%$ dos participantes afirmaram ter conhecimento de namoro entre alunos e professores. Cabe ressaltar que o fato de já ter apanhado ou ficado de castigo não teve influência sobre a avaliação que as crianças fizeram da escola $(p>.05)$. Apenas $6,7 \%$ das crianças que responderam ao questionário consideraram a escola em que estudavam como ruim ou muito ruim. Em contrapartida, $47,5 \%$ a classificaram como regular, e $45,8 \%$ como boa ou muito boa.

Gráfico 1. Participantes da pesquisa, segundo idade e série.

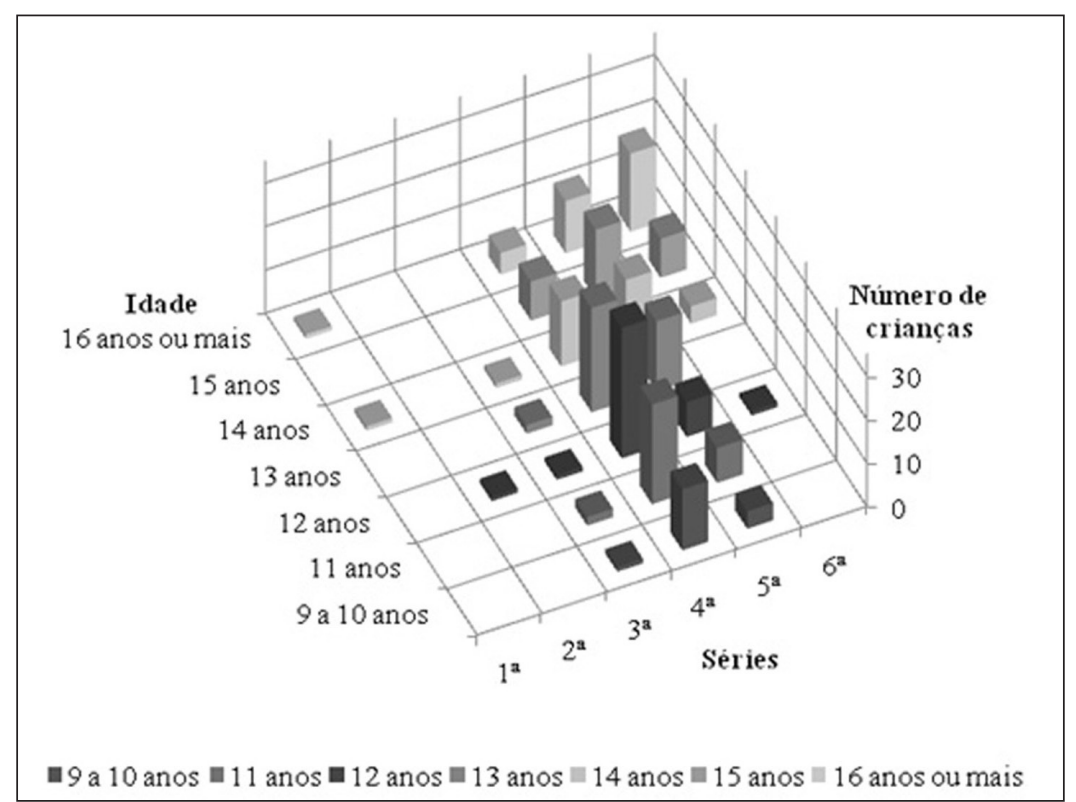

Educação (Porto Alegre), v. 39, n. 1, p. 11-21, jan.-abr. 2016 
Apesar do elevado número de participantes que declarou já ter sido vítima de alguma agressão por parte dos professores, a maioria $(66,1 \%)$ afirmou que se sente segura na escola e 58,6\% disseram que recebem ajuda do professor quando precisam. Para $69 \%$ dos participantes, no entanto, os professores faltam muito às aulas e $38,4 \%$ disseram que já souberam que algum professor ou funcionário da escola foi trabalhar alcoolizado.

Com relação às suas perspectivas de futuro acadêmico, $77 \%$ das crianças e adolescentes afirmaram acreditar que vão conseguir completar o ensino primário. Esse percentual diminuiu significativamente quando a pergunta foi sobre o ensino secundário, que apenas $52,7 \%$ dos participantes declararam ter esperanças de concluir.

\section{ESTUDO II}

Este estudo teve como objetivo investigar a situação dos direitos da criança e do adolescente e a ocorrência de castigos físicos em escolas de ensino público primário de Angola. Além disso, o estudo também teve como intuito conhecer a opinião dos estudantes acerca da escola em que estudavam e de sua relação com ela.

\section{Método}

O estudo II foi conduzido nas mesmas escolas do estudo I e realizou entrevistas semi-estruturadas em grupo. Não houve um limite predeterminado de participantes. Em média, cada entrevista contou com a participação de aproximadamente 30 crianças, a partir de 6 anos de idade. As pequisadoras buscaram dar espaço a todos que quisessem manifestar sua opinião e deixar as crianças livres para se expressarem sem qualquer tipo de apreensão ou censura.

As entrevistas em grupo ocorreram todas nas escolas, mas em uma ampla variedade de condições. Em Luanda, província pouco afetada diretamente pelas guerras e onde as três escolas visitadas possuíam estrutura física tradicional, com salas, mesas e cadeiras, as entrevistas foram realizadas em ambientes fechados. Nas 12 escolas das outras quatro províncias, no entanto, essa estrutura era muitas vezes inexistente. Bié e Moxico, por exemplo, estão entre as províncias que mais foram afetadas pelos conflitos (GUHA-SAPIR; GÓMEZ, 2006). Cunene e Huíla foram menos atingidas, mas também apresentam estruturas precárias. Em virtude disso, nesses locais as entrevistas aconteceram em espaços abertos, em salas de aula ao ar livre, embaixo de árvores ou ao redor da escola, lugares em que as crianças tinham aula. Embora teoricamente, e seguindo os preceitos de rigor metodológico, esses não sejam os locais ideais para a condução de entrevistas, essas condições são as mesmas que os participantes vivenciam todos os dias nas escolas devido à falta de estrutura a qual estão habituados. Assim, considerando a proposta da inserção ecológica e o objetivo de experenciar a realidade dos participantes em uma pesquisa naturalística, levá-los a um lugar fechado - supostamente mais apropriado - significaria criar uma situação artificial de pesquisa, o que não condizia com o intuito do estudo. Contudo, mesmo nas entrevistas realizadas ao ar livre, as pesquisadoras atentaram para que as únicas pessoas presentes fossem aquelas envolvidas no debate, preservando assim a opinião dos participantes e a confidencialidade dos relatos inerentes ao próprio grupo.

Todas as respostas e discussões geradas pelas entrevistas foram registradas manualmente pelas pesquisadoras em cadernos de campo, nos quais anotaram o sentido global das respostas. Em casos específicos, foi realizado o registro literal das falas que mais se destacaram por serem enfatizadas pelas crianças e por representarem o posicionamento do grupo como um todo. As pesquisadoras tentaram fazer a palavra circular entre todos os participantes dos grupos, respeitando, no entanto, aqueles que queriam participar, mas não manifestar verbalmente suas opiniões.

Além dos momentos formais do estudo, a equipe de pesquisa também se envolveu em uma série de outras atividades com os participantes, tais como brincadeiras, jogos, danças, caminhadas pela escola conduzidas pelas crianças, observações e, especialmente, conversas informais. Essa interação contribuiu para um melhor entendimento sobre os modos de funcionamento do contexto observado e tornou possível para a equipe entrar em contato com as mais diversas situações, comuns ou inesperadas, que fazem parte do cotidiano das escolas e dos participantes. Esses momentos propiciaram a emergência de assuntos e informações que frequentemente são fundamentais para a compreensão de alguns aspectos da realidade, mas que nem sempre são acessíveis através da utilização exclusiva de entrevistas formais e questionários.

\section{Resultados}

Os resultados deste estudo serão apresentados em três tópicos, de acordo com os principais assuntos abordados pelos participantes: estrutura da escola, castigos físicos e escola dos sonhos.

\section{Estrutura da escola}

A descrição realizada pelas crianças a respeito de suas escolas evidenciou uma série de questões percebidas por elas como problemáticas, a começar pela infraestrutura oferecida. Em todas as instituições visitadas, com exceção daquelas situadas em Luanda (capital), várias salas de aula funcionavam ao ar livre, embaixo de árvores ou encostadas em muros, por exemplo. Em um determinado 
local, duas turmas de terceira classe, cada uma com cerca de 40 alunos, dividiam uma mesma árvore, cada qual sentando em lados opostos do tronco, uma de frente para a outra.

De acordo com as crianças, algumas condições climáticas, como o calor e o vento, dificultam a concentração e a aprendizagem. Além disso, elas disseram não gostar de quando chove, pois as aulas são canceladas: "Quando tem chuva, não tem escola". Os participantes também mencionaram a falta de mesas, cadeiras, quadros e material didático que, quando existentes, estavam em estado precário de conservação. Muitas vezes, as cadeiras utilizadas na escola eram levadas de casa pelos alunos ou substituídas por pedras, latas e troncos.

Segundo os participantes, a falta de transporte escolar fazia com que, nos locais mais afastados dos centros urbanos, as crianças precisassem percorrer grandes distâncias até a escola, onde relataram chegar cansadas, com fome e com sede, o que comprometia sobremaneira a sua aprendizagem. A falta de água potável, merenda e energia elétrica, comum a todas as instituições, também foi apresentada como um dos principais entraves para a aprendizagem: "A sala fica escura e não dá pra ver o quadro". As crianças também relataram desconforto com a ausência ou má conservação dos banheiros.

As crianças consideraram ser muito difícil aprender nessas condições em virtude, principalmente, do desconforto e da falta de materiais básicos como cadernos e lápis para copiar o que os professores ditam ou escrevem no quadro. Elas ressaltaram que, em virtude dessa falta de condições necessárias ao ensino e à aprendizagem, "há coisas que não estamos a aprender". Para a maioria delas, no entanto, a qualidade do ensino é boa e, se os alunos não conseguem aprender, é porque brincam, conversam ou porque "a cabeça não é boa". A maior parte dos participantes creditou a responsabilidade por dificuldades de aprendizado aos próprios alunos, e não a uma possível má qualidade do ensino, aos professores ou à precariedade infraestrutural das escolas.

\section{Castigos fisicos}

Ainda com relação às dificuldades enfrentadas pelos alunos, os relatos sobre a utilização de castigos físicos estiveram presentes tanto nas entrevistas quanto nas conversas informais com as crianças. Todos os alunos afirmaram já ter visto algum colega apanhar dos professores ou ser punido, tendo de ficar ajoelhado com os braços abertos e esticados, segurando uma pedra em cada mão. Segundo as crianças, também era comum os professores puxarem as orelhas dos alunos e darem batidas com a mão fechada, conhecidas como "cocos", em suas cabeças. Em muitas escolas, houve relatos de que os professores tinham um pedaço de madeira guardado, curiosamente chamado de "Maria das Dores" pelas crianças, para bater nas mãos, braços, pernas e nádegas dos alunos. Essa informação foi confirmada nas observações realizadas pela equipe de pesquisa. De acordo com os alunos entrevistados, os motivos que levam os professores a adotarem tais práticas são variados e envolvem tanto questões disciplinares quanto acadêmicas: atraso, conversa na sala de aula, não realização de tarefas ou alguma dificuldade de aprendizagem apresentada pela criança, principalmente para ler e/ou escrever.

As crianças, apesar de terem sido unânimes ao dizer que não gostam de ficar de castigo ou de apanhar dos professores, argumentaram que os castigos físicos auxiliam na aprendizagem e são até mesmo necessários para que ela ocorra. Como ilustra a fala de uma delas: "Se não bater, não aprende". Muitas também afirmaram concordar com a utilização desse tipo de método para controlar a disciplina em sala de aula: "Se falar com a boca não entende, tem que ser com o chicote". Segundo a maioria dos alunos, os docentes agem corretamente ao aplicar castigos físicos. Esse pensamento foi corroborado pela afirmação de que preferem os professores que batem aos que não batem, pois assim aprendem.

De maneira geral, as crianças e adolescentes não pareceram identificar essas práticas como violentas, e sim como educativas. Quando questionados sobre outras possibilidades de atuação dos docentes para solucionar os problemas em sala de aula, as opiniões dos alunos se dividiram: alguns acreditavam que seria possível resolver as questões com uma conversa, com uma simples chamada de atenção ou com uma explicação melhor: "Se o professor ensinar bem e explicar direitinho, não precisa bater". Outros, porém, mantiveram a posição de que os castigos físicos são as melhores estratégias.

Apesar de nos dias atuais ser oficialmente proibida, a utilização de violência contra a criança na escola é uma prática socialmente estabelecida no país, há algumas décadas, e legitimada como uma forma de controle da disciplina e de resolução dos conflitos na sala de aula. Esse atraso em assumir outras práticas que estabeleçam um clima de aprendizagem favorável em sala de aula pode ser compreendido, e não justificado, ao se considerar o déficit formativo das equipes docentes e gestoras das escolas angolanas. Ainda é precária - e urgente - a inserção desses profissionais em contextos de formação e discussão sobre formas de educar que tomem os alunos como sujeitos dos processos de ensino e aprendizagem, dos quais deveriam ser coautores e partícipes fundamentais. Soma-se a isso um possível desconhecimento sobre questões relativas aos direitos humanos e aos direitos da criança e do adolescente.

As agressões físicas relatadas não foram a única forma de violência identificada nas escolas angolanas. 
Em uma das instituições visitadas na província do Moxico, quando perguntado sobre o tratamento dado pelos professores para meninos e meninas, um grupo de meninos entrevistados afirmou que "os professores gostam de conquistar as meninas". Segundo eles, as meninas sofreriam ameaças de reprovação e perseguição fora do ambiente escolar caso recusassem o envolvimento sexual com o professor. Essas informações foram negadas com veemência por docentes e também pela direção escolar, mas confirmadas pelas meninas, que afirmaram não ter comunicado nada a familiares ou a instâncias superiores por medo de represálias. Ao contrário do que ocorre com os castigos físicos, no entanto, o abuso sexual parece ser condenado pela sociedade angolana. A legislação prevê sanções administrativas e penais para os abusadores. Segundo as crianças, no entanto, dificilmente um docente é punido quando esse tipo de violência ocorre, porque, com receio de serem desacreditadas e perseguidas, as vítimas raramente fazem algum tipo de denúncia.

\section{Escola dos sonhos}

Ao serem questionadas sobre como seria a escola dos seus sonhos, as crianças enfatizaram elementos básicos, como questões relacionadas à infraestrutura. Segundo elas, nessa escola, "as salas de aula teriam paredes, janelas". Além disso, seria "bonita e limpa", teria água potável e energia elétrica. Elas também mencionaram o desejo de ter cadeiras e mesas em boas condições e em quantidade suficiente para todos, pois assim "ninguém precisaria sentar no chão ou em cima de pedras" para assistir às aulas. As salas também seriam equipadas com quadros negros de boa qualidade, e todos os alunos teriam os materiais necessários para estudar, tais como livros, cadernos, lápis, borracha e mochila.

As crianças enfatizaram a necessidade de ter acesso a merenda e transporte gratuitos e também lembraram os espaços de lazer, de quadras esportivas e de brinquedos como "bolas, escorregador, balanços e bonecas". No que diz respeito aos professores que dariam aula na escola dos seus sonhos, os participantes mencionaram que, além de ensinar bem, gostariam que eles fossem carinhosos e não batessem. Em uma escola ideal, portanto, a frase "se não bater, não aprende" não faria sentido.

\section{DISCUSSÃo}

A elevada defasagem escolar e a dificuldade de leitura mesmo em crianças e adolescentes de séries avançadas, identificada no estudo 1, e os relatos dos participantes no estudo 2 revelaram uma série de dificuldades existentes no ensino público primário angolano. Em termos macrossistêmicos, a história de Angola desde seus primórdios, e mais recentemente durante as duas guerras, contribuiu para a formatação que as escolas do país possuem hoje, tanto em termos físicos quanto estruturais. Uma escola é construída e constituída ao longo do tempo por pessoas, mas também por eventos históricos, pela cultura e pela sociedade nas quais estão inseridas e por uma série de outros contextos e instâncias que atuam sobre ela. As crianças que hoje frequentam o ensino primário eram pequenas quando o acordo de paz foi selado no país e conviveram durante pouco tempo com a guerra. Contudo, os reflexos do conflito ainda são muito presentes em suas vidas acadêmicas, seja na precariedade das estruturas escolares, que foram destruídas ou pouco conservadas, na formação insuficiente dos docentes ou na rigidez hierárquica que caracteriza as instituições de ensino e a sociedade como um todo.

Considerando as necessidades pessoais e desenvolvimentais das crianças, no entanto, esse contexto rígido e hierárquico pode não ser o ideal para o amadurecimento das competências potencialmente geradas pelos processos proximais (BRONFENBRENNER; EVANS, 2000). Apesar de progressivamente mais complexas e constantes ao longo do tempo, as interações entre crianças, professores, diretores e escola parecem carecer de reciprocidade, visto que são caracterizadas por desequilíbrio de poder e autoritarismo, inclusive com a utilização de coerção física e emocional (LISBOA; KOLLER, 2004).

A reciprocidade nas relações é importante não apenas para a efetividade do processo de ensino e aprendizagem, mas também para o desenvolvimento afetivo e emocional dos alunos. Além disso, ao ter de conviver permanentemente com a sensação de medo, as crianças podem vivenciar bloqueios socioemocionais que comprometem seu pleno desenvolvimento saudável, afetam sua inserção social construtiva e estimulam o sentimento de autopercepção negativa. Com esses tipos de relações estabelecidas em seu processo formativo inicial, essas crianças dificilmente serão jovens e adultos que buscarão soluções pacíficas para seus conflitos, diferenças, oposições e divergências, perpetuando uma cultura de violência e hierarquização na sociedade. Perceb0,2e-se, assim, que o processo de violência da escola (CHARLOT, 2002), caso não seja erradicado, pode trazer consequências destrutivas para o desenvolvimento humano pretendido pelo país.

O reconhecimento dessas lacunas no sistema educativo angolano levou o país a elaborar uma Reforma Educativa, com o intuito de melhorar a sua qualidade de ensino e corrigir esse tipo de distorção. De acordo com o autor angolano Azancot-Menezes (2010), contudo, ainda é preciso ocorrer uma série de avanços para que esse objetivo seja alcançado, informação corroborada pelos resultados encontrados neste estudo. No que diz respeito à 
proibição dos castigos, por exemplo, foi possível perceber que, além dos castigos físicos continuarem sendo aplicados, existe ainda uma legitimação social do uso de práticas violentas como forma de controle da disciplina e de resolução dos conflitos na escola, sobretudo em sala de aula.

A violência contra a criança em Angola tem sua origem no modelo macrossistêmico que sustenta as relações sociais no país. Diversos pressupostos históricos, econômicos, sociais e culturais convergem para justificar as práticas violentas autorizadas, de forma oficial ou não, pela sociedade. Dentre eles, parece estar a concepção da criança e do adolescente como pessoas que ainda não atingiram a idade necessária para fazer jus aos seus direitos. Apesar da adesão a pactos internacionais de reconhecimento aos infanto-juvenis, que posicionam crianças e adolescentes como sujeitos de direitos, e não meros objetos de direitos, essa mudança de posição parece ainda não ter sido totalmente absorvida pela sociedade angolana.

Apesar dos esforços governamentais e não governamentais empreendidos no país, a situação dos direitos infanto-juvenis ainda é precária em Angola como um todo e, particularmente, no sistema de ensino público primário, foco deste estudo. A presente pesquisa identificou uma série de violações aos direitos da criança nas escolas visitadas. Essas transgressões estão em todos os três pilares da Convenção sobre os Direitos da Criança provisão, proteção e participação (VERHELLEN, 2000) -, visto que foram identificadas falta de condições básicas de higiene e saúde, falta de luz, água, alimentação e transporte, condições precárias para ensino e aprendizagem, violência física e sexual, falta de diálogo e impossibilidade de manifestação de opiniões contrárias à das autoridades escolares sem ameaça de punição.

\section{ConClusão}

Assim como o restante da população, as crianças e os adolescentes angolanos naturalmente também estão expostos a um ciclo de violência estrutural cuja atuação pode ser verificada com clareza nas escolas, locais nos quais as práticas punitivas adotadas pelo corpo docente são tidas como educativas e são justificadas até mesmo pelos alunos. No entanto, esse dado não pode ser desconsiderado de um contexto maior de luta pela garantia dos Direitos Humanos, em especial a garantia dos direitos da criança e do adolescente que, a partir do estudo realizado, mostrou-se urgente.

Ao contrário do que acontece em muitos países em desenvolvimento, em especial na América Latina, nos quais as questões dos direitos humanos já têm um caminho construído e hoje estão voltados para o princípio da inclusão e do direito à diversidade (CANDAU, 2007), em Angola a garantia de direitos básicos, como o acesso à educação e o combate à violência física e institucional, ainda é incipiente. No plano político e legal, esses direitos estão garantidos. Na prática, contudo, a violência permanece legitimada, até mesmo pelas vítimas, como ilustra a fala que dá nome a este artigo: "Se não bater, não aprende".

Nesse contexto, emerge a importância da implementação de uma política de Educação em Direitos Humanos $^{2}$ em que os seguintes elementos fundamentais se façam presentes nos ambientes educativos: a visão integral dos direitos; uma educação para o "nunca mais"; o desenvolvimento de processos orientados à formação de sujeitos de direito e atores sociais; e a promoção do empoderamento individual e coletivo, especialmente dos grupos sociais marginalizados ou discriminados (CANDAU e SCAVINO, 2013, p. 61).

Considerando que os principais agentes das violências impostas às crianças na realidade angolana são os professores, essa política de formação em educação em direitos humanos se torna ainda mais urgente. Uma das estratégias mais eficazes seria a inserção da temática nos programas de formação inicial e continuada desses profissionais, bem como nos currículos das escolas, de modo a informar e empoderar as crianças para que não permaneçam na condição única de objeto de direitos e possam, assim, tornar-se também sujeitos ativos da reivindicação e defesa de seus direitos.

É preciso considerar que os professores, no entanto, também estão inseridos nesse todo complexo que é a sociedade angolana. A formação que recebem é insuficiente, quando existente, e eles também não têm acesso às condições básicas de vida e trabalho. Além disso, têm como referência a educação que receberam na condição de alunos - provavelmente pautada também em violência -, visto que a maioria não passou por processos de formação técnico-pedagógica, principalmente os que estão alocados fora da capital. Ratifica-se aqui a necessidade de que essa formação dos docentes também discuta e problematize os aspectos culturais da sociedade angolana, abarcando sua complexidade e diversidade. Mas que também se comprometa com a eliminação de todas e quaisquer práticas violentas - sejam elas físicas, psicológicas ou simbólicas -, e caminhe na direção da construção de uma nação que eduque e proteja sua infância e juventude.

\footnotetext{
2 Peter Fritzsche (apud CANDAU e SCAVINO, 2013, p. 61) "assinala que a educação em Direitos Humanos se assenta num tripé: conhecer e defender seus direitos; respeitar a igualdade de direitos dos outros; e estar tão comprometido quanto possível com a defesa da educação em Direitos Humanos dos outros. Supõe a comunicação de saberes e valores e desenvolve uma compreensão das dimensões jurídica e política, assim como moral e preventivo-pedagógica, dos Direitos Humanos".
} 
Segundo Nsamenang (2009), os estudos desenvolvidos com crianças africanas em geral utilizam modelos europeus patologizantes e desconectados da realidade local, que não consideram o desenvolvimento das crianças em contexto. O mesmo autor, em palestra proferida em 2010, criticou o caráter assistencialista de muitas pesquisas realizadas em solo africano e destacou o que chamou de pedido silencioso das crianças africanas: "Por favor, antes de tentar nos ajudar, nos conheça" (NSAMENANG, 2010). Seguindo essa linha de pensamento, a pesquisa apresentada neste artigo pretendeu dar voz e atenção às crianças e aos adolescentes angolanos, conhecer as escolas em que estudam por meio dos seus olhos e escutar atentamente suas necessidades e aspirações. Ao mesmo tempo, foi preciso atentar aos limites para a diferenciação entre o que é cultural e o que é violação de diretos humanos, dos quais as crianças estavam sendo sistematicamente alienadas.

A relação dos participantes deste estudo com a escola como um todo é permeada por vários sentimentos, que envolvem ao mesmo tempo o reconhecimento da importância desse espaço em suas vidas, o prazer em estudar e também o incômodo com a série de dificuldades que enfrentam cotidianamente. A escola dos sonhos das crianças e adolescentes angolanos é uma escola simples, com chão, paredes, teto e janelas, que atende a requisitos básicos promotores de saúde e de bem-estar. Não é uma escola com muitos computadores ou outros recursos tecnológicos avançados, mas um local em que todos têm cadernos, lápis e borracha para estudar e aprender. As crianças e os adolescentes angolanos participantes desta pesquisa sonham com uma escola que ainda não conhecem e, mesmo que talvez não tenham consciência disso, desejam uma escola em que seus direitos básicos sejam respeitados.

$\mathrm{Na}$ medida em que convidou as crianças a refletirem ativamente sobre a realidade que vivenciam em suas escolas e por ter propiciado momentos de debate e escuta, a pesquisa descrita neste artigo espera ter sido também uma forma de intervenção (MORAIS, 2009). O pouco tempo que as pesquisadoras permaneceram em cada escola pode ser considerado uma das limitações dessa investigação, assim como o fato de terem abarcado apenas cinco das 18 províncias do país. Apesar disso, a equipe considera ter atingido seu propósito de conhecer a opinião das crianças e dos adolescentes a respeito de suas escolas e a situação dos direitos da criança nessas instituições.

Esse conhecimento nos permite afirmar que é fundamental e está em curso no país a articulação de políticas que deverão promover a reestruturação do sistema educativo angolano com vistas à garantia de direitos. Isso envolve a criação de infraestrutura adequada, a promoção da aprendizagem, da inclusão, da saúde, da segurança, da proteção e do engajamento comunitário e, também, maior sensibilidade às questões de gênero, tão complexas na sociedade angolana. A convergência dessas políticas concorre para a transformação necessária na educação do país e, consequentemente, para a consolidação de uma sociedade democrática, justa e cidadã. E a cooperação com organismos internacionais ligados aos direitos humanos, além do estreitamento dos laços diplomáticos e institucionais com países em desenvolvimento que têm registrado avanços nessas políticas, como o Brasil, são um forte indicativo dos esforços empreendidos e de que essas mudanças estão em curso.

\section{REFERÊNCIAS}

ANGOLA. Constituição da República de Angola. Luanda, Angola, 2010.

AZANCOT-MENEZES, M. Um olhar sobre a implementação da Reforma Educativa em Angola: estudo de caso nas províncias de Luanda, Huambo e Huíla. Luanda: Rede Angolana da Sociedade Civil de Educação para Todos, 2010. 73 p.

BRONFENBRENNER, U. The ecology of human development: experiments in nature and design. Cambridge: Harvard University Press, 1979, 330 p.

BRONFENBRENNER, U. Ecological systems theory. In: BRONFENBRENNER, U. (Org.). Making human beings human: bioecological perspectives on human development. Thousand Oaks, CA: Sage, 2005 (original publicado em 1992). p. 106-173.

BRONFENBRENNER, U.; EVANS, G. W. Developmental science in the $21^{\text {st }}$ century: emerging questions, theoretical models, research designs and empirical findings. Social Development, v. 9, n. 1, p. 115-125, 2000.

CANDAU, V. M. F; SCAVINO, S. B. Educação em Direitos Humanos e formação de educadores. Educação, Porto Alegre, v. 36, n. 1, p. 59-66, jan.-abr. 2013.

CANDAU, V. M. F. A configuração de uma educação em Direitos Humanos. In: SILVEIRA, R. M. G. et al. (Org.). Educação em Direitos Humanos: fundamentos teóricos-metodológicos. João Pessoa: Ed. Universitária, 2007. p. 399-412.

CECCONELLO, A. M.; KOLLER, S. H. Inserção ecológica na comunidade: uma proposta metodológica para o estudo de famílias em situação de risco. Psicologia: Reflexão e Crítica, Porto Alegre, v. 16, n. 3, p. 515-524, 2003.

CECCONELLO, A. M.; KOLLER, S. H. Inserção ecológica na comunidade: uma proposta metodológica para o estudo de famílias em situação de risco. In: KOLLER, S. H. (Org.). Ecologia do desenvolvimento humano: Pesquisa e intervenção no Brasil. São Paulo: Casa do Psicólogo, 2004. p. 267-291.

CHARLOT, B. A violência na escola: como os sociólogos franceses abordam essa questão. In: Sociologias, Porto Alegre, n. 8, p. 432-443, jul.-dez. 2002.

CONSELHO NACIONAL DA CRIANÇA - CNAC. IV Fórum Nacional da Criança - Documento final: conclusões e recomendações. Luanda, Angola, 2009. 32 p. 
DELL'AGLIO, D. D.; HUTZ, C. S. Estratégias de coping de crianças e adolescentes em eventos estressantes com pares e com adultos. Psicologia USP, São Paulo, v. 13, n. 2, p. 203-225, 2002.

ESCHILETTI PRATI, L.; PAULA COUTO, M. C. P. DE; MOURA, A.; POLETTO M.; KOLLER, S. H. Revisando a inserção ecológica: uma proposta de sistematização. Psicologia: Reflexão e Crítica, Porto Alegre, v. 21, n. 1, p. 160-169, 2008.

FEINSTEIN, S.; MWAHOMBELA, L. Corporal punishment in Tanzania schools. International Review of Education, Hamburgo, v. 56, p. 399-410, 2010.

FRAGA, P. C. P. Os sentidos da violência. Cadernos de Ciências Humanas - Especiaria, v. 9, n. 15, p. 231-236, 2006.

GATES, S., HEGRE, H.; NYGARD, H. M.; STRAND, H. Development consequences of armed conflict. World Development, v. 40, n. 9, p. 1713-1722, 2012.

GUHA-SAPIR, D., GÓMEZ, V. T. Angola: the human impact of war. A data review of field surveys in Angola between 19992005. Brussels: CRED, 2006. 36 p.

LEAGUE OF NATIONS. Geneva Declaration of the Rights of the Child. 1924. Disponível em: <http://www.un-documents. net/gdrc1924.htm>. Acesso em: 18 nov. 2009.

LISBOA, C.; KOLLER, S. H. O microssistema escolar e os processos proximais: exemplos de investigações científicas e intervenções práticas. In: KOLLER, S. H. (Org.). Ecologia do desenvolvimento humano: pesquisa e intervenção no Brasil. São Paulo: Casa do Psicólogo, 2004. p. 337-353.

MACHEL, G. Impact of armed conflict on children. New York: UNICEF, 1996.

MINISTÉRIO DA EDUCAÇÃO DE ANGOLA - MED. Reflexões sobre educação em Angola. Luanda, 2010a. Disponível em: <http://www.med.gov.ao/PublicacoesD. aspx?Codigo $=651>$. Acesso em: 18 nov. 2010 .

MINISTÉRIO DA EDUCAÇÃO DE ANGOLA - MED. Relatório da pesquisa Escolas Amigas da Criança em Angola. Luanda: Aldeia Global, 2010b. 184 p.

MORAIS, N. A. Trajetórias de vida de crianças e adolescentes em situação de vulnerabilidade social: entre o risco e a proteção, 2009. 231 p. Tese (Doutorado em Psicologia) Instituto de Psicologia, Universidade Federal do Rio Grande do Sul, Porto Alegre.

NSAMENANG, A. B. Conceptualizing developmental assessment within Africa's cultural settings. In: GRIGORENKO, E. L. (Org.). Multicultural Psychoeducational Assessment. New York: Springer Publishing Company, 2009. p. 95-132.

NSAMENANG, A. B. Africa's contributions to human development science. In: $21^{\text {st }}$ BIENNAL MEETINGS OF THE ISSBD. Lusaka, Zambia, 2010.

ONYANGO, P. The impact of armed conflict on children. Child Abuse Review, v. 21, p. 219-229, 1998

ORGANIZAÇÃO DAS NAÇÕES UNIDAS - ONU. Declaração Universal dos Direitos Humanos, 1948. Disponível em: <http://www.unicef.org/brazil/pt/resources 10133.htm>. Acesso em: 15 out. 2013.
ORGANIZAÇÃO DAS NAÇÕES UNIDAS - ONU. Declaration of the rights of the child. Disponível em: $<$ http:// www.cirp.org/library/ethics/UN-declaration/>. Acesso em: 18 jun. 2009.

ORGANIZAÇÃO DAS NAÇÕES UNIDAS - ONU. Convenção sobre os Direitos da Criança, 1989. Disponível em: <http://www.unicef.org/brazil/pt/resources 10120.htm>. Acesso em: 15 out. 2013

ORGANIZAÇÃO DAS NAÇÕES UNIDAS - ONU. Protocolo facultativo para a Convenção sobre os Direitos da Criança sobre o envolvimento de crianças em conflitos armados, 2000. Disponível em: <http://www.unicef.org/brazil/pt/ resources 10124.htm>. Acesso em: 10 maio 2014.

PALUDO, S. S.; KOLLER, S. H. Inserção ecológica no espaço da rua. In KOLLER, S. H. (Org.). Ecologia do desenvolvimento humano: pesquisa e intervenção no Brasil. São Paulo: Casa do Psicólogo, 2004. p. 219-244.

POIRIER, T. The effects of armed conflict on schooling in Sub-Saharan Africa. International Journal of Educational Development, v. 32, p. 341-351, 2012.

SACCO, A. M. "Como é a escola dos teus sonhos?": direitos da criança, educação e inserção ecológica em Angola. 2011. 65 p. Dissertação (Mestrado em Psicologia) - Instituto de Psicologia, Universidade Federal do Rio Grande do Sul, Porto Alegre.

SAVE THE CHILDREN. A situação social da criança em Angola. Luanda: Save The Children, 2010.

PROGRAMA DAS NAÇÕES UNIDAS PARA O DESENVOLVIMENTO - UNDP. Relatório do Desenvolvimento Humano 2010. Nova York: PNUD, 2010. 217 p.

PROGRAMA DAS NAÇÕES UNIDAS PARA O DESENVOLVIMENTO - UNDP. Relatório do Desenvolvimento Humano 2013. Nova York: PNUD, 2013. 202 p.

SALMÓN, G. E. O longo caminho da luta contra a pobreza e seu alentador encontro com os direitos humanos. Revista Internacional de Direitos Humanos, v. 4, n. 7, p. 152-167, 2007.

SHELMAN, E. A.; LAZORITZ, S. The Mary Ellen Wilson case and the beginning of Children's Rights in 19th Century America. North Carolina: McFarland \& Company, 2005. $247 \mathrm{p}$.

SOUZA, S. A. G. P. A Declaração dos Direitos da Criança e a Convenção sobre os Direitos da Criança: direitos humanos a proteger em um mundo em guerra. 2001. Disponível em: $<$ http://jus2.uol.com.br/doutrina/texto.asp?id=2568 $>$. Acesso em: 18 nov. 2009.

WEBER, M. A.; GUZZO, R. S. L. Respeito às crianças na educação infantil: Visão de pais e educadores. Pesquisas e Práticas Psicossociais, v. 3, n. 2, p. 187-198, 2009.

VERHELLEN, E. Convention on the rights of the child, 3. ed. Leuven: Garant, 2000. 193 p.

Submetido em: 21/07/2014

Aprovado em: 27/07/2015 